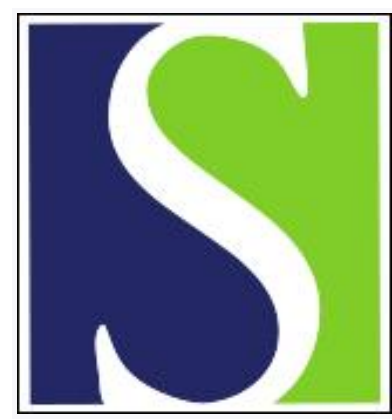

Scand J Work Environ Health 2011;37(5):383-393

https://doi.org/10.5271/sjweh.3163

Published online: 15 Apr 2011, Issue date: Sep 2011

The effectiveness of participatory ergonomics to prevent low-back and neck pain - results of a cluster randomized controlled trial

by Driessen MT, Proper KI, Anema JR, Knol DL, Bongers PM, van der Beek AJ

Affiliation: EMGO Institute for Health and Care Research, Department of Public and Occupational Health, van der Boechorststraat 7, 1081 BT Amsterdam, the Netherlands. h.anema@vumc.nl

Refers to the following text of the Journal: 2002;28(1):18-24

The following articles refer to this text: 2014;40(1):57-65; 2017;43(3):226-233; 2017;43(6):526-539; 2018;44(2):113-133; 2019;45(2):146-157; 2020;46(4):429-436

Key terms: back pain; low-back pain; MSD; musculoskeletal disorder; neck pain; participatory ergonomics; randomized controlled trial; RCT; worker

This article in PubMed: www.ncbi.nlm.nih.gov/pubmed/21499671

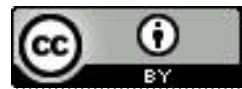




\title{
The effectiveness of participatory ergonomics to prevent low-back and neck pain - results of a cluster randomized controlled trial
}

\author{
by Maurice T Driessen, MSc, ${ }^{1,2}$ Karin I Proper, PhD, 1, 2 Johannes R Anema, PhD, MD, 1, 2 Dirk L Knol, \\ PhD, ${ }^{3}$ Paulien M Bongers, PhD, 1,2,4 Allard J van der Beek, PhD 1,2
}

\begin{abstract}
Driessen MT, Proper KI, Anema JR, Knol DL, Bongers PM, J van der Beek AJ. The effectiveness of participatory ergonomics to prevent low-back and neck pain - results of a cluster randomized controlled trial. Scand J Work Environ Health 2011;37(5):383-393. doi:10.5271/sjweh.3163
\end{abstract}

Objective The aim of this randomized controlled trial (RCT) was to investigate the effectiveness of the Stay@ Work participatory ergonomics (PE) program to prevent low-back and neck pain.

Methods A total of 37 departments were randomly allocated to either the intervention (PE) or control group (no PE). During a six-hour meeting, working groups followed the PE steps and composed and prioritized ergonomic measures aimed at preventing low-back and neck pain. Subsequently, working groups were requested to implement the ergonomic measures in the departments. The primary outcomes were low-back and neck pain prevalence and secondary outcomes were pain intensity and duration. Data were collected by questionnaires at baseline, and after 3-, 6-, 9-, and 12-months follow-up. Additionally, the course of low-back and neck pain (transitions from no symptoms to symptoms and from symptoms to no symptoms) was modeled.

Results The randomization procedure resulted in 19 intervention departments ( $\mathrm{N}=1472$ workers) and 18 control departments ( $\mathrm{N}=1575$ workers). After 12 months, the intervention was not more effective than the control group in reducing the prevalence of low-back and neck pain or reducing pain intensity and duration. PE did not increase the probability of preventing low-back pain [odds ratio (OR) $1.23,95 \%$ confidence interval $(95 \% \mathrm{CI}) 0.97-1.57$ ] or neck pain (OR 1.01, 95\% CI 0.74-1.40). However, PE increased the probability of recovering from low-back pain (OR 1.41, 95\% CI 1.01-1.96), but not from neck pain (OR 0.95, 95\% CI 0.72-1.26).

Conclusion PE neither reduced low-back and neck pain prevalence nor pain intensity and duration nor was it effective in the prevention of low-back and neck pain or the recovery from neck pain. However, PE was more effective in the recovery from low-back pain.

Key terms back pain; musculoskeletal disorder; MSD; RCT; worker.

Low-back pain (LBP) and neck pain (NP) are serious public health problems in Western industrialized countries (1, 2). In the Netherlands, the 12-month prevalence of LBP is estimated to be $44.4 \%$ and $28 \%$ for NP (3), and both are common among the working population as well. LBP and NP have unfavorable consequences for the individual worker in terms of pain and disability $(1,4)$, but are also a burden for society and companies in terms of costs due to medical healthcare consumption, work absenteeism, and productivity loss at work $(5,6)$. In view of this impact, there is an obvious need for effective prevention strategies. To prevent LBP and NP, various strategies (ie, lumbar supports, advice or education on postures and working methods, physical exercise programs, lifting aids, new chairs, and pause software) have already been conducted at the workplace. Nevertheless, except for physical exercise programs, none of these strategies has proven to be effective in preventing LBP or NP (7-10).

A promising strategy is participatory ergonomics (PE). Supported by the management, PE enables

1 Body@Work TNO VU University Medical Center, Research Center Physical Activity, Work and Health, Amsterdam, the Netherlands.

2 Department of Public and Occupational Health \& the EMGO Institute for Health and Care Research, VU University Medical Center, Amsterdam, the Netherlands.

3 Department of Epidemiology and Biostatisics \& the EMGO Institute for Health and Care Research, VU University Medical Center, Amsterdam, the Netherlands.

4 TNO Quality of Life, Hoofddorp, the Netherlands.

Correspondence to: Johannes R Anema, EMGO Institute for Health and Care Research, Department of Public and Occupational Health, van der Boechorststraat 7, 1081 BT Amsterdam, the Netherlands. [E-mail: h.anema@vumc.nl] 
workers to control their own work activities and empowers them to change their workspace (11). In both the Canadian and Dutch settings, PE resulted in a significantly earlier return to work among sick-listed workers with LBP compared to the control group that received usual care (12-14). A systematic review showed that PE was a successful strategy to reduce musculoskeletal disorders (MSD) such as LBP and NP (15). However, many of the studies included in the review suffered from methodological shortcomings (ie, lack of a proper randomization procedure or a lack of a control group), making their findings at risk for bias. Several randomized controlled trials (RCT) have been conducted to evaluate the effectiveness of PE as a strategy to prevent MSD and/or to reduce MSD-related pain (16-19). However, no RCT on PE has specifically focused on LBP and NP prevention. In order to draw more definite conclusions on the effectiveness of PE, it was necessary to conduct another RCT.

To this end, the current cluster RCT, the so-called Stay@Work study, investigated the effectiveness of a PE program on the prevention of LBP and NP among a large and heterogeneous population of workers.

\section{Methods}

This cluster RCT was conducted at the departments of four Dutch companies: a railway transportation company, an airline company, a university including its university medical hospital, and a steel company. The Medical Ethics Committee of the VU University Medical Center approved the study protocol. More details on the study design and methods have been described elsewhere (20).

\section{Study population}

All workers within the participating departments were allowed to participate in the study. Because the focus was on LBP and NP prevention, only workers meeting the following criteria at baseline were included in the analyses: (i) aged between 18-65 years; (ii) not pregnant; and (iii) no cumulative sick leave period $>4$ weeks due to LBP or NP in the previous 3 months.

\section{Control group}

Before filling out the baseline questionnaire, workers from both the intervention and control departments were requested to watch three short ( 45 seconds) educational movies about the prevention of LBP and NP. The movies were used as a sham intervention and can be considered as an ineffective strategy to prevent LBP and NP (7).

\section{Intervention}

Intervention departments received the Stay@Work PE program, which has been described in detail elsewhere (20). Briefly, each intervention department formed a working group, in which eight workers and one department manager (or its representative) participated as members. Under the guidance of a trained ergonomist, the working group followed the steps of the PE program during a 6-hour meeting. All decisions during the meeting were made by the working group members and were based on consensus. All working group meetings were focused on the prevention of LBP and NP in the department. By following the steps of the PE program, the working group brainstormed about, evaluated, and prioritized the top three risk factors for LBP and NP. Subsequently, the working group brainstormed about, evaluated, and prioritized the top three ergonomic measures. All information about the prioritized risk factors and ergonomic measures were written down in an implementation plan. The working group had to implement the prioritized ergonomic measures in their departments within three months. To enhance implementation, two or three members of each working group followed a 4-hour ergo-coach (implementation) training. An optional second (1-hour) working group meeting was held to evaluate and/or modify the implementation process. Altogether, working groups prioritized 66 ergonomic measures: 32 individual ergonomic measures (ie, improving awareness regarding ergonomics, worksite visits, and physical activity programs), 27 physical ergonomic measures (ie, ergonomic redesign or modification, new equipment, and manual handling aids), and 7 organizational ergonomic measures (ie, pause software installation, job rotation, and restructuring management style). Approximately one third of the prioritized ergonomic measures were implemented in the intervention departments (21).

\section{Outcome measures and data collection}

Baseline responders were sent follow-up questionnaires after 3-, 6-, 9-, and 12 months. The primary outcome measure was the prevalence of LBP and NP and was assessed every 3 months using the Dutch musculoskeletal questionnaire (DMQ) (22). On a 4-point scale, the DMQ asked about the presence of LBP and NP, respectively, in the previous 3 months $(1=$ no, never, $2=y e s$, sometimes; $3=y e s$, regularly; and $4=y e s$, always). Prevalence was determined by combining the categories "no, never" with "yes, sometimes" into "no LBP or NP" and the categories "yes, regularly" and "yes, always" into "LBP or NP". Secondary outcomes were also assessed every 3 months using the 11-point Von Korff scales and encompassed: (i) LBP and NP mean pain intensity in the 
previous 3 months (ranging from $0=$ "no symptoms" to $10=$ "worst imaginable"), and (ii) LBP and NP duration, defined as the total number of days with pain experienced in the past 3 months (23).

\section{Potential confounders}

At baseline, socio-demographic information was collected, including: age, gender, and level of education (22). Moreover, the DMQ was also used to obtain information (yes/no) on physical risk factors (ie, heavy manually lifting and carrying, awkward positions, driving machines, and neck flexion) of LBP and NP (22). Psychosocial risk factors of LBP and NP were assessed using the Job Content Questionnaire. Workers rated 25 items on a 4-point scale ( $1=$ totally disagree, $2=$ disagree, $3=$ agree, $4=$ totally agree). By combining various items, the following dimensions were constructed: skill discretion, decision authority, psychosocial job demands, supervisor support, and co-worker support. The decision latitude dimension was constructed by combining skill discretion and decision authority, whereas the overall social support dimension was constructed by combining supervisor- and co-worker support (24).

\section{Ergonomic co-interventions}

Ergonomic measures that were implemented in the department, but were not the result of the PE intervention, were registered as "ergonomic co-interventions". Information on these co-interventions was obtained from the workers using a questionnaire. Furthermore, by means of a questionnaire, department managers were also asked (i) whether other co-interventions, such as LBP and NP prevention programs (eg, chair massage, fitness programs, and lifestyle programs), had been conducted in their department during the period under study, and (ii) if any reorganizations had occurred in their department.

\section{Sample size}

The sample size calculation showed that an initial study population of 2076 workers was needed to statistically find a $25 \%$ reduction of LBP and NP prevalence, with a power of $80 \%$ and a significance level of 0.05 (20).

\section{Randomization}

Randomization was performed at the level of the department. Based on their workload, the 37 participating departments were pre-stratified into various categories of demanding work: mentally, mixed mentally and physically, light physically, or heavy physically (25). Within each company, a pair of departments with comparable workloads was randomly allocated to either the interven- tion (PE) or control (no PE) group. The randomization procedure was performed by an independent research assistant using a computer-generated randomization program. Only department managers were informed about the randomization outcome (20).

\section{Blinding}

The intervention made it impossible to blind workers, researchers, working group members and department managers. However, department workers were kept blind to the study design and were, therefore, blinded to the group assignment.

\section{Statistical analysis}

All analyses were performed according to the "intention to treat" principle. To assess the success of the randomization, descriptive statistics were used to compare the baseline measurement of the groups. Multilevel analysis was used to evaluate the intervention effects for all outcome variables. Multilevel analysis enables adjustment for the clustering of observations within matched randomization pairs, departments, and workers. In this study, four levels were identified: (i) time (five occasions) (ii) workers, (iii) departments, and (iv) matched randomization pairs. After 6 and 12 months, over $30 \%$ of the baseline responders were lost to follow-up. Under the assumption that data were missing at random (26), the method of maximum likelihood yields unbiased estimates. A nice feature of the maximum likelihood procedure is that all collected data on the outcomes can be used.

For each outcome variable, two analyses were performed: (i) a crude analysis (ie, the differences between intervention and control group at 3-, 6-, 9-, and 12-months follow-up adjusted for the corresponding baseline differences on the outcome variable), and (ii) an adjusted analysis, encompassing an analysis as above but adjusted for potential confounders (eg, gender, age, level of education, or physical and psychosocial risk factors). For all analyses, the intervention effect of interest was the interaction between group and measurement time (27). Since potential confounders did not change the intervention effect by more than $10 \%$, the results of the crude analysis are presented. No significant interactions $(\mathrm{P}<0.05)$ were found with main workload performed, indicating that effect modification did not occur. Therefore, the results of subgroup analyses on workload are not presented.

In Stata version 10.0 (Stata Corp, College Station, TX, USA), logistic mixed models were used to study the intervention effects on LBP and NP prevalence [odds ratio (OR)]. In SPSS version 15.0, (SPSS Inc, Chicago, IL, USA), linear mixed models were used to study the intervention effects on pain intensity and duration for 
three groups: (i) the whole study population including all workers with or without symptoms at baseline (primary and secondary prevention), (ii) workers without symptoms at baseline (primary prevention), (iii) workers with symptoms at baseline (secondary prevention). For all analyses a two-tailed significance level of $\mathrm{P}<0.05$ was considered statistically significant.

\section{Transition models}

LBP and NP are episodic, indicating that over time symptoms come and go. To study the intervention effects on the primary and secondary prevention of LBP and NP, transitions models were used in which the presence of LBP in the past three months and the presence of NP in the past three months were incorporated in the model. The transition models enabled the investigation of the effectiveness of the PE intervention on the course of LBP and NP. In a so-called first order Markov transition model, the probability of getting LBP given no LBP at the previous time interval and the reverse probability of not getting LBP given LBP at the previous time interval were modeled simultaneously by means of a logistic mixed model $(28,29)$. Modeling simultaneously indicates that the transition model takes into account the previous state in order to determine whether an individual is at risk of developing symptoms. The course of NP was similarly modeled. Transition models were conducted using the gllamm procedure in Stata version 10.0 , and were not adjusted for potential confounders.

\section{Results}

\section{Participants flow}

Figure 1 presents the flow of departments and participants in this trial. A total of 37 departments $(\mathrm{N}=5798$ workers) were randomized, 19 of which were allocated to the intervention group ( $\mathrm{N}=2852$ workers) and 18 to the control group ( $\mathrm{N}=2946$ workers). The baseline questionnaire was sent to 5695 workers, of whom 3232 (57\%) responded. All together, 3047 workers met the inclusion criteria (1472 and 1575 in the intervention and control group, respectively) and were approached for the follow-up measurements.

\section{Loss to follow-up}

After 12 months, the loss to follow-up on the primary outcome measure was $40 \%$ in the intervention and $37 \%$ in the control group. Complete follow-up data on the primary outcome measure (LBP and NP) was derived from 1280 workers.

\section{Baseline characteristics}

Table 1 presents the baseline characteristics of the departments and the workers in the intervention group and the control group. At baseline, no meaningful differences between workers in the intervention and the control group were found for either the potential confounders or the primary and secondary outcomes.

\section{Effects on the prevalence of low-back and neck pain}

Table 2 shows that, during the 12-month follow-up period, PE was not more effective compared with the control group in reducing the prevalence of LBP and NP.

\section{Effects on pain intensity and pain duration}

Low-back pain. Figures 2 A-F show the mean low-back pain intensity and mean pain duration at baseline and after 3-, 6-, 9-, and 12-months of follow-up for 3 groups: (i) workers with or without LBP at baseline, (ii) workers with LBP at baseline, and (iii) workers without LBP at baseline. The figures show that during the 12-month follow-up period, PE was not more effective than the control group in the reduction of pain intensity and pain duration. Among workers with LBP at baseline, PE statistically significantly reduced pain intensity in the first nine months. However, the effect was not sustained beyond 12 months. Regarding the other LBP outcomes, several statistically significant reductions were found but again reductions were small and disappeared after 12 months.

Neck pain. In figures $3 \mathrm{~A}-\mathrm{F}$, the results on NP intensity and pain duration at baseline and after 3-, 6-, 9-, and 12-months of follow-up are presented. Similar to the LBP results, the results on NP are presented separately for three groups. The results show that, compared to the control group, $\mathrm{PE}$ did not result in statistically significant reductions in pain intensity and duration. Regarding NP intensity, workers in the intervention group perceived statistically significant higher levels of pain intensity. Nonetheless, differences were small and not sustained.

\section{Effects on the course of low-back and neck pain}

Derived from the transition model, table 3 shows the intervention effects on the two transition probabilities: (i) getting LBP and NP (symptoms) given no LBP and NP (no symptoms) respectively, at the previous time interval; and (ii) the reverse transition probability of not getting LBP and NP (no symptoms) given LBP and NP (symptoms) respectively, at the previous time interval. The findings on LBP and NP indicated that PE did not statistically significantly increase the probability of preventing LBP and NP during the 12-month follow-up 


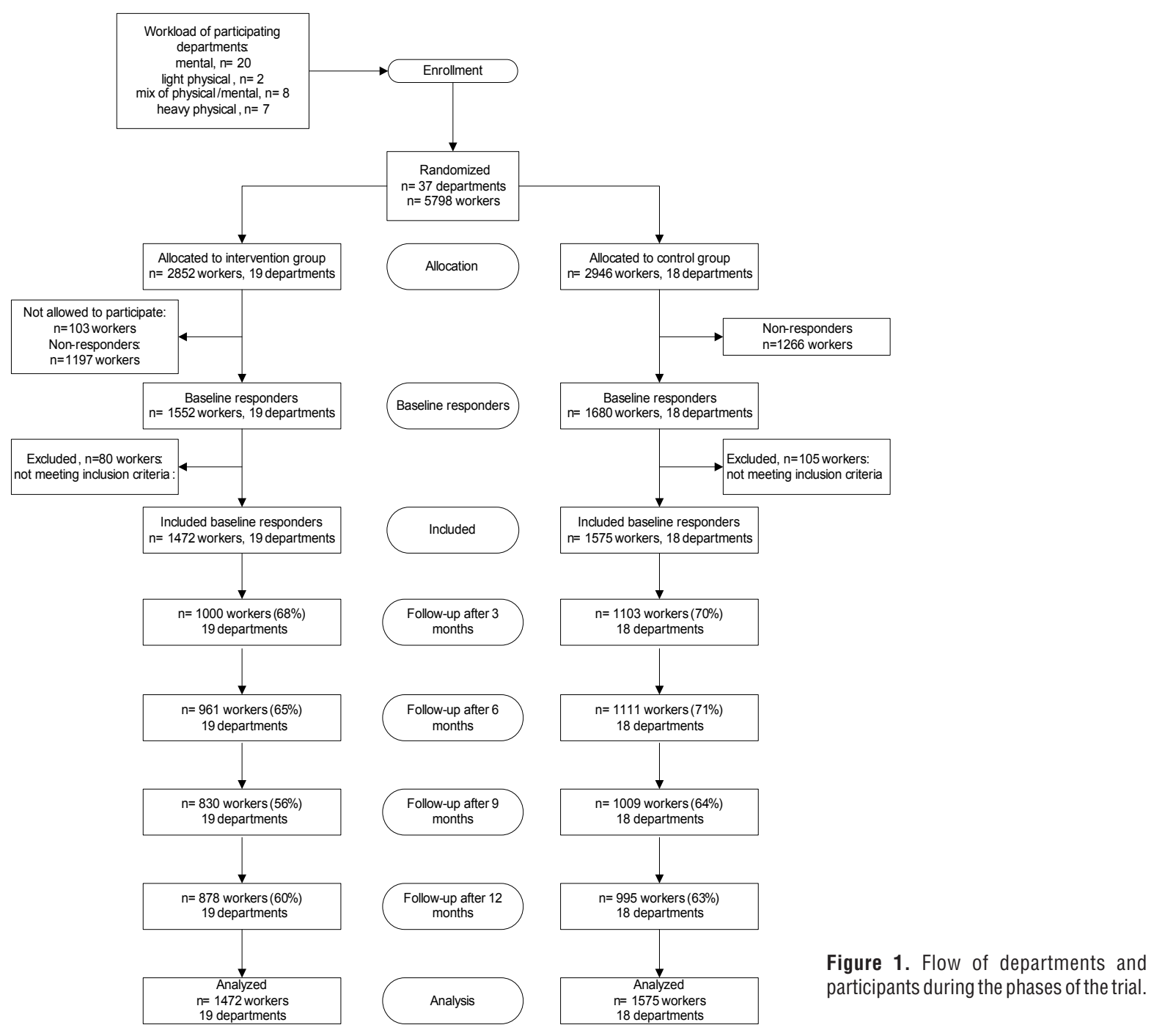

period. However, the probability of recovering from LBP was statistically significantly increased among workers who received PE [OR 1.41, 95\% confidence interval $(95 \% \mathrm{CI}) 1.01-1.96]$. PE did not increase the probability of recovering from NP.

\section{Ergonomic co-interventions}

In the 12-month follow-up period, almost an equal amount of ergonomic co-interventions (ergonomic measures that were not the result of the PE intervention) were implemented in the intervention $(\mathrm{N}=883)$ and control departments $(\mathrm{N}=850)$. Most often the ergonomic cointerventions encompassed information about ergonomics, new desks/chairs, and job modifications. None of the departments implemented other co-interventions, such as LBP and NP prevention program (ie, health promotion programs) during the 12-month follow-up period, and no departmental reorganizations occurred during this period.

\section{Discussion}

\section{Principal findings}

This study showed that the Stay@Work PE program was not more effective than the control group in reducing LBP and NP prevalence during the 12-month follow-up period. PE was not effective in preventing LBP, but was more successful in helping individuals recover from LBP (OR 1.41, 95\% CI 1.01-1.96). Regarding NP, no differences between the intervention and control group were found with respect to prevention or recovery. PE was not effective in reducing pain intensity and duration, either for LBP or NP.

\section{Strengths and weaknesses of the study}

Distinctive strengths of our work include: the cluster RCT study design, its statistical power, the use of a 
Table 1. Baseline characteristics. [SD=standard deviation.]

\begin{tabular}{|c|c|c|c|c|c|c|c|c|}
\hline & \multicolumn{4}{|c|}{ Intervention group } & \multicolumn{4}{|c|}{ Control group } \\
\hline & $\mathrm{N}$ & $\%$ & Mean & SD & $\mathrm{N}$ & $\%$ & Mean & SD \\
\hline $\begin{array}{l}\text { Department characteristics a } \\
\text { Workload departments } \\
\text { Mental } \\
\text { Light physical } \\
\text { Mix: mental/physical } \\
\text { Heavy physical }\end{array}$ & $\begin{array}{r}10 \\
1 \\
4 \\
4\end{array}$ & & & & $\begin{array}{r}10 \\
1 \\
4 \\
3\end{array}$ & & & \\
\hline $\begin{array}{l}\text { Worker characteristics }{ }^{\text {b }} \\
\text { Age (years) } \\
\text { Male gender } \\
\text { Education }{ }^{c} \\
\text { Lower education } \\
\text { Intermediate education } \\
\text { Higher education }\end{array}$ & $\begin{array}{l}202 \\
572 \\
690\end{array}$ & $\begin{array}{r}59 \\
13.8 \\
39.1 \\
47.1\end{array}$ & 41.9 & 11.1 & $\begin{array}{l}126 \\
579 \\
868\end{array}$ & $\begin{array}{r}57 \\
8.0 \\
26.8 \\
55.2\end{array}$ & 42.1 & 10.7 \\
\hline $\begin{array}{l}\text { Work-related psychosocial factors } \\
\text { Decision latitude (range 8-32 points) } \\
\text { Skill discretion (range 5-20 points) } \\
\text { Decision authority (range 3-12 points) }\end{array}$ & & & $\begin{array}{r}24.8 \\
15.9 \\
9.0\end{array}$ & $\begin{array}{l}3.6 \\
2.3 \\
1.7\end{array}$ & & & $\begin{array}{r}25.3^{\mathrm{c}} \\
16.2^{\mathrm{c}} \\
9.1^{\mathrm{c}}\end{array}$ & $\begin{array}{l}3.1 \\
2.0 \\
1.5\end{array}$ \\
\hline $\begin{array}{l}\text { Social support (range } 8-32 \text { points) } \\
\text { Co-worker support (range } 4-16 \text { points) } \\
\text { Supervisor support (range } 4-16 \text { points) } \\
\text { Psychosocial job demands (range } 5-20 \text { points) }\end{array}$ & & & $\begin{array}{l}23.3 \\
12.1 \\
11.2 \\
12.8\end{array}$ & $\begin{array}{l}3.0 \\
1.5 \\
2.1 \\
2.3\end{array}$ & & & $\begin{array}{r}23.3 \\
12.2^{c} \\
11.1 \\
12.8^{c}\end{array}$ & $\begin{array}{l}2.8 \\
1.4 \\
2.1 \\
2.2\end{array}$ \\
\hline $\begin{array}{l}\text { Work-related physical factors } \\
\text { Often manually lift loads }>20 \mathrm{~kg} \\
\text { Often manually carries load }>20 \mathrm{~kg} \\
\text { Often drives machines (lorry, crane, bulldozer) } \\
\text { Work in heavily awkward position for a prolonged time } \\
\text { Often bends neck forwards or hold neck in a forward bent posture }\end{array}$ & & & $\begin{array}{l}211 \\
105 \\
248 \\
307 \\
508\end{array}$ & $\begin{array}{r}14.3 \\
7.1 \\
16.8 \\
20.9 \\
34.5\end{array}$ & & & $\begin{array}{r}277^{c} \\
149^{c} \\
124^{c} \\
293 \\
531\end{array}$ & $\begin{array}{r}17.6 \\
9.5 \\
7.9 \\
18.6 \\
33.7\end{array}$ \\
\hline $\begin{array}{l}\text { Low-back pain, whole population } \\
\text { Having had low-back pain in the past } 3 \text { months } \\
\text { Mean pain intensity in the past } 3 \text { months } \\
\text { Duration in the past } 3 \text { months }\end{array}$ & 404 & 27.4 & $\begin{array}{r}2.2 \\
12.0\end{array}$ & $\begin{array}{r}2.4 \\
21.7\end{array}$ & 415 & 26.3 & $\begin{array}{r}2.1 \\
11.5\end{array}$ & $\begin{array}{r}2.3 \\
21.0\end{array}$ \\
\hline $\begin{array}{l}\text { Population with low-back pain at baseline } \\
\text { Mean pain intensity in the past } 3 \text { months } \\
\text { Duration in the past } 3 \text { months }\end{array}$ & & & $\begin{array}{r}4.9 \\
35.6\end{array}$ & $\begin{array}{r}2.3 \\
29.7\end{array}$ & & & $\begin{array}{r}4.6 \\
34.7\end{array}$ & $\begin{array}{r}2.2 \\
29.0\end{array}$ \\
\hline $\begin{array}{l}\text { Population without low-back pain at baseline } \\
\text { Mean pain intensity in the past } 3 \text { months } \\
\text { Duration in the past } 3 \text { months }\end{array}$ & & & $\begin{array}{l}1.1 \\
3.1\end{array}$ & $\begin{array}{l}1.5 \\
5.0\end{array}$ & & & $\begin{array}{l}1.1 \\
3.3\end{array}$ & $\begin{array}{l}1.5 \\
6.0\end{array}$ \\
\hline $\begin{array}{l}\text { Neck pain, whole population } \\
\text { Having had neck pain in the past } 3 \text { months } \\
\text { Mean pain intensity in the past } 3 \text { months } \\
\text { Duration in the past } 3 \text { months }\end{array}$ & 319 & 21.7 & $\begin{array}{l}1.7 \\
9.7\end{array}$ & $\begin{array}{r}2.2 \\
19.8\end{array}$ & 325 & 20.6 & $\begin{array}{l}1.7 \\
8.9\end{array}$ & $\begin{array}{r}2.1 \\
18.6\end{array}$ \\
\hline $\begin{array}{l}\text { Population with neck pain at baseline } \\
\text { Mean pain intensity in the past } 3 \text { months } \\
\text { Duration in the past } 3 \text { months }\end{array}$ & & & $\begin{array}{r}4.6 \\
25.3\end{array}$ & $\begin{array}{r}2.1 \\
29.3\end{array}$ & & & $\begin{array}{r}4.4 \\
32.3\end{array}$ & $\begin{array}{r}2.2 \\
28.4\end{array}$ \\
\hline $\begin{array}{l}\text { Population without neck pain at baseline } \\
\text { Mean pain intensity in the past } 3 \text { months } \\
\text { Duration in the past } 3 \text { months }\end{array}$ & & & $\begin{array}{l}0.9 \\
2.6\end{array}$ & $\begin{array}{l}1.4 \\
5.5\end{array}$ & & & $\begin{array}{l}0.9 \\
2.8\end{array}$ & $\begin{array}{l}1.4 \\
6.9\end{array}$ \\
\hline
\end{tabular}

a Intervention group $\mathrm{N}=19$ departments, control group $\mathrm{N}=18$ departments

b Intervention group $\mathrm{N}=1472$, control group $\mathrm{N}=1575$

c $P<0.05$

large study population as well as the inclusion of workers from diverse task groups with various workloads. The generalizability of our study findings towards the whole working population, therefore, is high. Further, randomization at the department level minimized possible contamination between workers from the intervention and control groups. Repeated measurements were used as well as standardized questionnaires to measure study outcomes (30). A limitation of this study is the considerable loss to follow-up rates on the primary and secondary outcomes found after 12 months. Unfortunately, loss to follow-up is a common problem among prevention studies (31). Checking our data for selective drop-out revealed that non-responders did not differ 

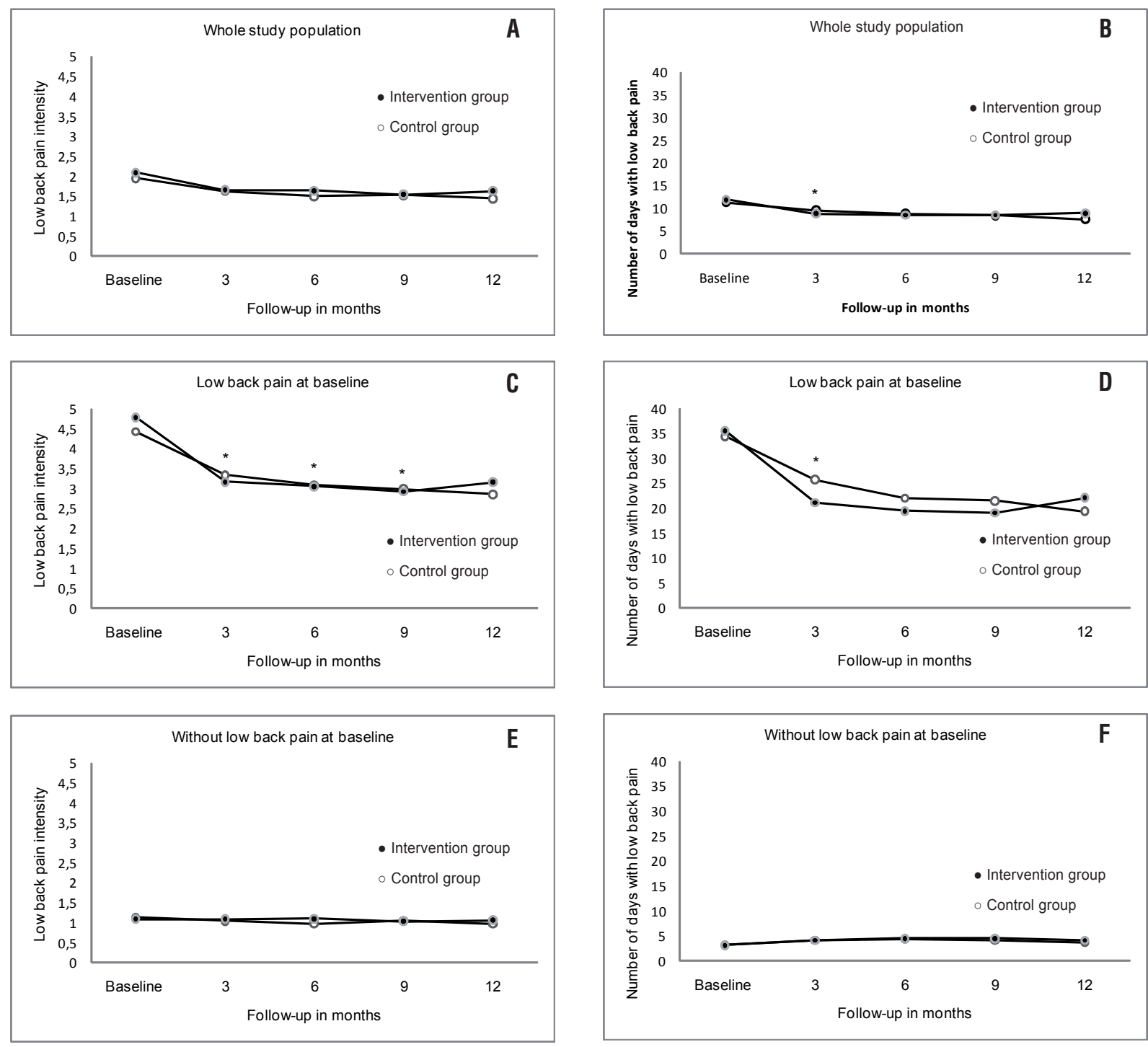

Figure 2. Model-based mean low back pain intensity and duration at baseline and after three, six, nine, and 12-month follow-up. ${ }^{*}$ denotes $P<0.05$. The baseline values may slightly differ from the descriptive baseline values as presented in table 1, because figures (A-F) present the baseline values obtained from the (linear) mixed models.

Table 2. Intervention effects a on the prevalence of low-back and neck pain during 12-month follow-up. Results of the logistic mixed models. [OR=0dds ratio; $95 \% \mathrm{Cl}=95 \%$ confidence interval.]

\begin{tabular}{lccc}
\hline & $\mathrm{OR}$ & $95 \% \mathrm{Cl}$ & P-value \\
\cline { 2 - 4 } Low-back pain & & & \\
3 months & 0.73 & $0.50-1.07$ & 0.11 \\
6 months & 0.87 & $0.59-1.30$ & 0.50 \\
9 months & 1.11 & $0.73-1.68$ & 0.63 \\
12 months & 1.16 & $0.77-1.77$ & 0.48 \\
Neck pain & & & \\
3 months & 1.28 & $0.83-1.97$ & 0.27 \\
6 months & 1.05 & $0.68-1.63$ & 0.83 \\
9 months & 0.75 & $0.47-1.19$ & 0.28 \\
12 months & 0.88 & $0.56-1.40$ & 0.60 \\
\hline
\end{tabular}

${ }^{a}$ Adjusted for baseline differences on the outcome measure. from responders on several important prognostic LBP and NP factors (ie, age, gender, prevalence, pain intensity and duration). Nevertheless, loss to follow-up rates $>30 \%$ can introduce selection bias and thereby affect the ability to draw firm conclusions (32). Another limitation is the follow-up period of 12 months, which may be too short to make preventive effects on LBP and NP visible (33). This pragmatic cluster RCT enabled us to study the effects of PE under real world conditions But it was unavoidable that a considerable number of ergonomic co-interventions were implemented - in almost equal quantities - in both intervention and control departments. These ergonomic co-interventions may have reduced the contrast between the two trial arms. 

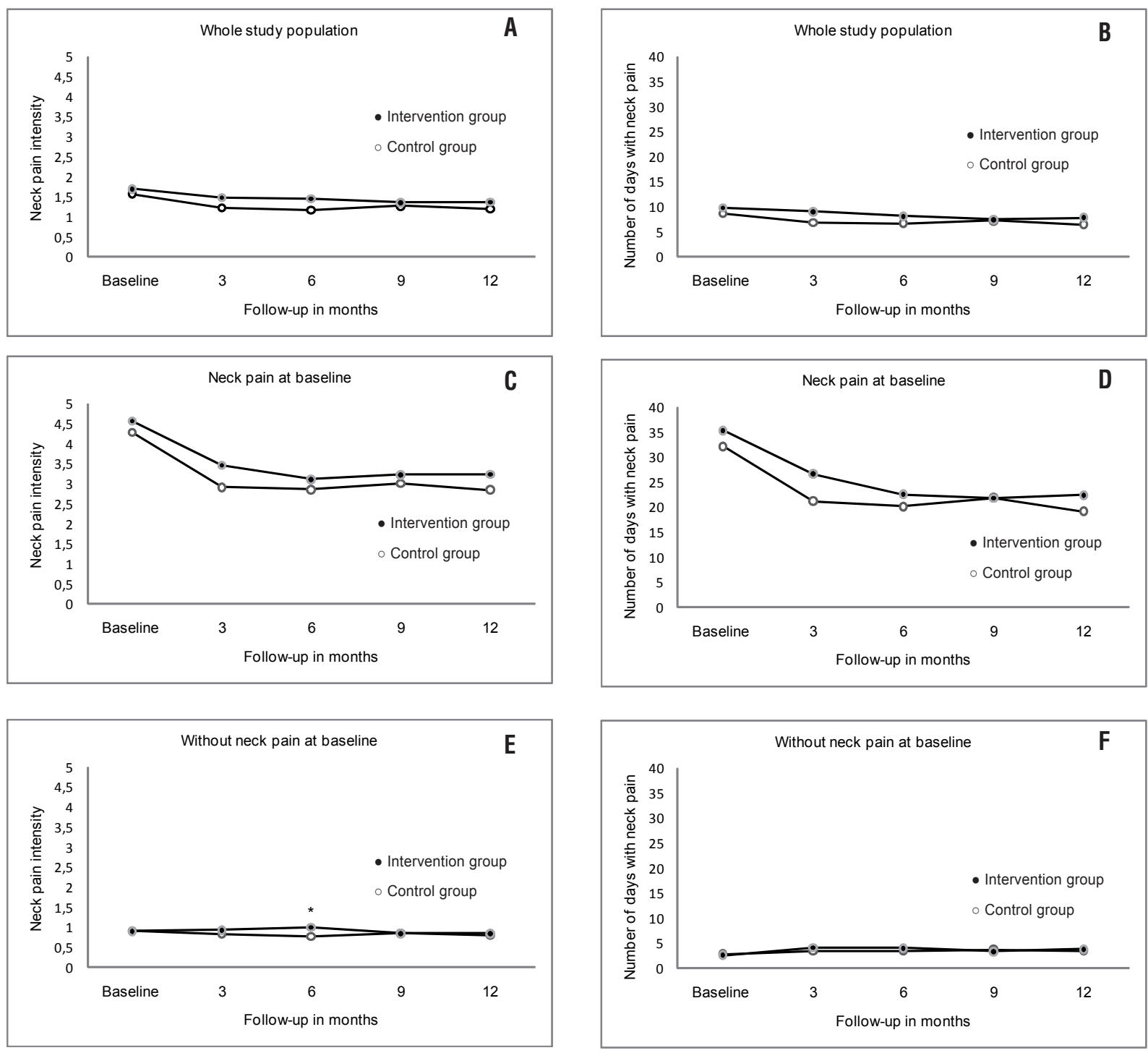

Figure 3. Model-based mean neck pain intensity and duration at baseline and after 3-, 6-, 9-, and 12-month follow-up. * denotes $P<0.05$. The baseline values may slightly differ from the descriptive baseline values as presented in table 1 , because figures $(A-F)$ present the baseline values obtained from the (linear) mixed models.

In their framework, Haines et al (11) presented several important items that have to be incorporated in PE interventions. According to this framework on PE, one of the main principles of PE is that workers themselves determine what they want to change in the workplace. In contrast to this principle, the current study decided in advance of the intervention that workers had to focus on LBP and NP. On the other hand, the high lifetime and 12-month prevalence rates of LBP and NP in the working population may justify our decision. Especially when the aim is prevention, it is necessary to make choices about where to intervene and to predefine the outcome measures of interests. The use of most of the other PE principles as described in the framework (ie, mix of participants and guidance by the ergonomist) were covered by our intervention.

\section{Comparison with other studies}

A systematic review concluded that PE was effective in reducing MSD and MSD-related symptoms (15). However, the results obtained from our study do not support this conclusion. Regarding LBP and NP, the findings obtained from other RCT are in accordance with our study findings. At 12-months follow-up, Morken et al (19) found that PE among workers in the aluminum industry was not more effective in preventing MSD (including LBP and NP) or reducing pain intensity. Also, Haukka et 
Table 3. Intervention effects during the 12-month follow-up period obtained from the transition model. [OR=0dds ratio; $95 \% \mathrm{Cl}=95 \%$ confidence interval.]

\begin{tabular}{lcccccccc}
\hline Outcome variable & \multicolumn{3}{c}{ From no symptoms to symptoms } & & \multicolumn{3}{c}{ From symptoms to no symptoms } \\
\cline { 2 - 4 } \cline { 7 - 9 } & $\mathrm{OR}$ & $95 \% \mathrm{Cl}$ & & P-value & & OR & $95 \% \mathrm{Cl}$ & $\mathrm{P}$-value \\
\hline Low-back pain & 1.23 & $0.97-1.57$ & 0.08 & & 1.41 & $1.01-1.96$ & 0.04 \\
Neck pain & 1.01 & $0.74-1.40$ & 0.92 & & 0.95 & $0.72-1.26$ & 0.71 \\
\hline
\end{tabular}

al (16) found after 12 months of follow-up that PE was not more effective than a control group in preventing MSD (including LBP and NP) or reducing pain intensity among kitchen workers. Among video display unit workers, it was found that, after 10 months of follow-up, PE was not more effective than a control group in reducing pain intensity (18). With respect to discomfort, the 12-month follow-up findings of Bohr et al (34) showed that PE was more effective than the control group in reducing upper-body discomfort among hospital workers. However, no significant reductions were found on lower-body discomfort (34). The discrepancy between the findings obtained from RCT and the conclusion of the systematic review may be caused by the inclusion of study designs other than RCT. It was found that non-randomized studies and studies that lacked a control group (ie, prepost studies) showed positive findings more often (15). When comparing our results with the findings obtained from other RCT on PE, the existing heterogeneity regarding the content of intervention, study population, outcome measurements, and follow-up duration should be considered. Nonetheless, the direction of their results indicate that $\mathrm{PE}$ is effective in neither primary prevention of LBP and NP nor reducing pain intensity and pain duration.

\section{Explanation of the findings}

There are several possible explanations for why our trial failed to demonstrate the effectiveness of the Stay@ Work PE program. The first explanation is the modest implementation rate. After six months, the PE program resulted in the implementation of approximately one third of the 66 prioritized in the intervention departments (21), and did not increase after 12 months. On the other hand, the RCT by Haukka et al (16) showed that high implementation rates in PE did not guarantee the finding of statistically significant effects on the prevention of MSD. Despite an implementation rate of $80 \%$ ( $\mathrm{N}=402$ ergonomic changes) PE was not more effective than the control group in preventing MSD or in reducing pain intensity $(16,35)$.

In line with the limited implementation, we found that PE was not able to reduce workload. Working groups most commonly prioritized the risk factors as: (i) unfavorable working posture, (ii) manually lifting and carrying of heavy loads, and (iii) problems with equip- ment/furniture. To resolve these risk factors, working groups prioritized mainly the more "simple" and less expensive ergonomic measures (ie, education on ergonomics or workplace visits by an expert or new desks, chairs or lifting devices). This is not surprising since the PE intervention evaluated all ergonomic measures on several implementation criteria (costs, complexity, compatibility, and implementable within 3 months).

Possibly, the efficacy of the ergonomic measures derived from the current PE program may be too limited to actually decrease risk factor exposure. A previous analysis conducted on the data of this study showed that, after six months, PE generally failed to statistically significantly reduce workers' exposure to the perceived physical and psychosocial risk factors for LBP and NP. Improvements due to PE were only found on decision authority and latitude (36) and even these were not sustained beyond the 12-months of follow-up (data not shown).

Another explanation for why the Stay@Work PE program was not shown to be effective is that at the very start of this study the prevalence rates of LBP and NP, pain intensity, and pain duration in both groups were relatively low. Consequently, little room was left for PE to further improve on these outcomes. Moreover, the low prevalence rates make it plausible that departments did acknowledge LBP and NP as an important issue. Subsequently, the workers and the managers of the working groups did not put personnel and financial efforts into implementing the prioritized ergonomic measures in the intervention departments. Nonetheless, it is uncertain whether a reduction on the investigated risk factors would have actually led to LBP and NP prevention. This uncertainty is partly due to the lack of consensus in the literature about the most important risk factors for LBP and NP occurrence $(37,38)$. Moreover, LBP and NP are of multifactorial origin, meaning that various risk factors (or combinations thereof) are responsible for their occurrence (39). In our study, most ergonomic measures were targeted on one single (prioritized) risk factor of LBP and NP. Subsequently, other risk factors for LBP and NP may have been targeted by the prioritized ergonomic measures. In addition, risk factors for LBP and NP that occur outside the workplace were not taken into account.

$\mathrm{PE}$ was effective in helping individuals recover from LBP. Additional analyses showed that prioritized 
ergonomic measures were not implemented more often among workers with LBP, and risk factor reduction was not different for workers with LBP. The risk factors for the occurrence of LBP differ from those for developing chronic LBP. In the latter, psychological factors (ie, stress and negative cognitive characteristics) as well as work environment factors (social support at work and job dissatisfaction) become increasingly important (40). Therefore, a possible explanation for the increased recovery may be that $\mathrm{PE}$ resulted in more attention being given to the problem of LBP and NP. Possibly, workers with LBP might have interpreted this positively because they perceived that managers were taking (their) LBP problem seriously and willing to undertake action.

\section{Concluding remarks}

After 12 months, the results of this large cluster-RCT showed that PE was not more effective than the control group in primary prevention of LBP and NP, neither did it help to reduce pain intensity nor pain duration. There were no significant differences between PE and the control group in helping individuals recover from NP. However, PE was more effective in the recovery from LBP.

\section{Acknowledgements}

This study was supported by a grant from the Netherlands Organization for Health Research and Development (ZonMw). Trial registration: ISRCTN27472278. The authors declare no competing interests.

\section{References}

1. Côté P, van der Velde G, Cassidy JD, Carroll LJ, Hogg-Johnson $\mathrm{S}$, Holm LW, et al. The burden and determinants of neck pain in workers: results of the Bone and Joint Decade 2000-2010 Task Force on Neck Pain and Its Associated Disorders. Spine (Phila Pa 1976). 2008;33(4 Suppl):S60-S74.

2. Freburger JK, Holmes GM, Agans RP, Jackman AM, Darter JD, Wallace AS, Castel LD, Kalsbeek WD, Carey TS. The rising prevalence of chronic low back pain. Arch Intern Med. 2009;169(3):251-8. doi:10.1001/archinternmed.2008.543.

3. Picavet HS, Schouten JS. Musculoskeletal pain in the Netherlands: prevalences, consequences and risk groups, the DMC(3)-study. Pain. 2003;102(1-2):167-78. doi:10.1016/ s0304-3959(02)00372-x.

4. Henschke N, Maher CG, Refshauge KM, Herbert RD, Cumming RG, Bleasel J, York J, Das A, McAuley JH. Prognosis in patients with recent onset low back pain in Australian primary care: inception cohort study. BMJ. 2008;337:a171. doi:10.1136/bmj.a171.
5. Dagenais S, Caro J, Haldeman S. A systematic review of low back pain cost of illness studies in the United States and internationally. Spine J. 2008;8(1):8-20. doi:10.1016/j. spinee.2007.10.005

6. Lambeek LC, van Tulder MW, Swinkels IC, Koppes LL, Anema JR, van Mechelen W. The trend in total cost of back pain in The Netherlands in the period 2002 to 2007. Spine (Phila Pa 1976). 2011 Jun;36(13):1050-8.

7. Bigos SJ, Holland J, Holland C, Webster JS, Battie M, Malmgren JA. High-quality controlled trials on preventing episodes of back problems: systematic literature review in working-age adults. Spine J. 2009;9(2):147-68. doi:10.1016/j. spinee.2008.11.001.

8. Burton AK, Balague F, Cardon G, Eriksen HR, Henrotin Y, Lahad A,et al. Chapter 2. European guidelines for prevention in low back pain: November 2004. Eur Spine J. 2006;15(2 Suppl):S136-S168.

9. Driessen MT, Proper KI, van Tulder MW, Anema JR, Bongers PM, van der Beek AJ. The effectiveness of physical and organisational ergonomic interventions on low back pain and neck pain: a systematic review. Occup Environ Med. 2010;67(4):277-85. doi:10.1136/oem.2009.047548.

10. Martimo KP, Verbeek J, Karppinen J, Furlan AD, Takala EP, Kuijer PP, Jauhiainen M, Viikari-Juntura E. Effect of training and lifting equipment for preventing back pain in lifting and handling: systematic review. BMJ. 2008;336(7641):429-31. doi:10.1136/bmj.39463.418380.BE.

11. Haines H, Wilson JR, Vink P, Koningsveld E. Validating a framework for participatory ergonomics (the PEF). Ergonomics. 2002;45(4):309-27. doi:10.1080/00140130210123516.

12. Anema JR, Steenstra IA, Bongers PM, de Vet HC, Knol DL, Loisel P, van Mechelen W. Multidisciplinary rehabilitation for subacute low back pain: graded activity or workplace intervention or both? A randomized controlled trial. Spine (Phila Pa 1976.). 2007;32(3):291-8.

13. Lambeek LC, van Mechelen W, Knol DL, Loisel P, Anema JR. Randomised controlled trial of integrated care to reduce disability from chronic low back pain in working and private life. BMJ. 2010;341:c1035. doi:10.1136/bmj.c1035.

14. Loisel P, Abenhaim L, Durand P, Esdaile JM, Suissa S, Gosselin L, Simard R, Turcotte J, Lemaire J. A populationbased, randomized clinical trial on back pain management. Spine (Phila Pa 1976.). 1997;22(24):2911-8.

15. Rivilis I, Van Eerd D, Cullen K, Cole DC, Irvin E, Tyson J, Mahood Q. Effectiveness of participatory ergonomic interventions on health outcomes: a systematic review. Appl Ergon. 2008;39(3):342-58. doi:10.1016/j. apergo.2007.08.006.

16. Haukka E, Leino-Arjas P, Viikari-Juntura E, Takala EP, Malmivaara A, Hopsu L, et al. A randomised controlled trial on whether a participatory ergonomics intervention could prevent musculoskeletal disorders. Occup Environ Med. 2008;65(12):849-56. doi:10.1136/oem.2007.034579.

17. Jensen LK, Friche C. Effects of training to implement new working methods to reduce knee strain in floor layers. A 
two-year follow-up. Occup Environ Med. 2008;65(1):20-7. doi:10.1136/oem.2006.028803.

18. Ketola R, Toivonen R, Hakkanen M, Luukkonen R, Takala EP, Viikari-Juntura E. Effects of ergonomic intervention in work with video display units. Scand J Work Environ Health. 2002;28(1):18-24.

19. Morken T, Moen B, Riise T, Hauge SHV, Holien S, Langedrag A, et al. Effects of a training program to improve musculoskeletal health among industrial workers - Effects of supervisors role in the intervention. Int $\mathrm{J}$ Ind Ergon 2002;30(2):115-27. doi:10.1016/S0169-8141(02)00090-2.

20. Driessen MT, Anema JR, Proper KI, Bongers PM, van der Beek AJ. Stay@Work: Participatory Ergonomics to prevent low back and neck pain among workers: design of a randomised controlled trial to evaluate the (cost-)effectiveness. BMC Musculoskelet Disord. 2008;9:145. doi:10.1186/14712474-9-145.

21. Driessen MT, Proper KI, Anema JR, Bongers PM, van der Beek AJ. Process evaluation of a Participatory Ergonomics programme to prevent low back pain and neck pain among workers. Implement Sci. 2010;5:65. doi:10.1186/1748-59085-65.

22. Hildebrandt VH, Bongers PM, van Dijk FJ, Kemper HC, Dul J. Dutch Musculoskeletal Questionnaire: description and basic qualities. Ergonomics. 2001;44(12):1038-55. doi:10.1080/00140130110087437.

23. Von Korff M, Ormel J, Keefe FJ, Dworkin SF. Grading the severity of chronic pain. Pain. 1992;50(2):133-49. doi:10.1016/0304-3959(92)90154-4.

24. de Jonge J, Reuvers MM, Houtman IL, Bongers PM, Kompier MA. Linear and nonlinear relations between psychosocial job characteristics, subjective outcomes, and sickness absence: baseline results from SMASH. Study on Musculoskeletal Disorders, Absenteeism, Stress, and Health. J Occup Health Psychol. 2000;5(2):256-68. doi:10.1037/1076-8998.5.2.256.

25. de Zwart BC, Broersen JP, van der Beek AJ, Frings-Dresen $\mathrm{MH}$, van Dijk FJ. Occupational classification according to work demands: an evaluation study. Int J Occup Med Environ Health. 1997;10(3);283-95.

26. von Hippel PT. Regression with missing Y's: an improved method for analyzing multiply imputed data. Sociol Methodol. 2007;37(1):83-117. doi:10.1111/j.1467-9531.2007.00180.x.

27. Fitzmaurice GM, Laird NM, Ware JH. Applied Longitudinal Analysis. New Jersey, USA: John Wiley \& Sons, 2004.

28. Berkhof J, Knol DL, Rijmen F, Twisk JW, Uitdehaag BJ, Boers M. Relapse-remission and remission-relapse switches in rheumatoid arthritis patients were modeled by random effects. J Clin Epidemiol. 2009;62(10):1085-94. doi:10.1016/j. jclinepi.2008.11.013.

29. Skrondal A, Rabe-Hesketh S. Generalized latent variable modeling: multilevel, longitudinal and structural equation models. Boca Raton, Florida: Chapman \& Hall/CRC, 2004. doi:10.1201/9780203489437.
30. Dionne CE, Dunn KM, Croft PR, Nachemson AL, Buchbinder $\mathrm{R}$, Walker BF, et al. A consensus approach toward the standardization of back pain definitions for use in prevalence studies. Spine (Phila Pa 1976.). 2008;33(1):95-103.

31. Galea S, Tracy M. Participation rates in epidemiologic studies. Ann Epidemiol. 2007;17(9):643-53. doi:10.1016/j. annepidem.2007.03.013.

32. Higgins JPT, Green S. Cochrane Handbook for Systematic Reviews of Interventions version 5.0.1 [updated September 2008]. The Cochrane Collaboration 2008. doi:10.1002/9780470712184.

33. Westgaard RH. Work-related musculoskeletal complaints: some ergonomics challenges upon the start of a new century. Appl Ergon. 2000;31(6):569-80. doi:10.1016/S00036870(00)00036-3.

34. Bohr PC, Evanoff BA, Wolf LD. Implementing participatory ergonomics teams among health care workers. Am J Ind Med. 1997;32(3):190-6. doi:10.1002/(SICI)10970274(199709)32:3<190::AID-AJIM2>3.0.CO;2-1.

35. Pehkonen I, Takala EP, Ketola R, Viikari-Juntura E, LeinoArjas P, Hopsu L, et al. Evaluation of a participatory ergonomic intervention process in kitchen work. Appl Ergon. 2009;40(1):115-23. doi:10.1016/j.apergo.2008.01.006.

36. Driessen MT, Proper KI, Anema JR, Knol DL, Bongers PM, van der Beek AJ. Participatory ergonomics to reduce exposure to psychosocial and physical risk factors for low back pain and neck pain: results of a cluster randomised controlled trial. Occup Environ Med. 2010 (epub ahead of print). doi:10.1136/ oem.2010.056739.

37. Lakke SE, Soer R, Takken T, Reneman MF. Risk and prognostic factors for non-specific musculoskeletal pain: a synthesis of evidence from systematic reviews classified into ICF dimensions. Pain. 2009;147(1-3):153-64. doi:10.1016/j. pain.2009.08.032.

38. Macfarlane GJ, Pallewatte N, Paudyal P, Blyth FM, Coggon D, Crombez G, et al. Evaluation of work-related psychosocial factors and regional musculoskeletal pain: results from a EULAR Task Force. Ann Rheum Dis. 2009;68(6):885-91. doi:10.1136/ard.2008.090829.

39. Bongers PM, IJmker S, van den Heuvel S, Blatter BM. Epidemiology of work related neck and upper limb problems: psychosocial and personal risk factors (part I) and effective interventions from a bio behavioural perspective (part II). J Occup Rehabil. 2006;16(3):279-302.

40. Hayden JA, Dunn KM, van der Windt DA, Shaw WS. What is the prognosis of back pain? Best Pract Res Clin Rheumatol. 2010;24(2):167-79. doi:10.1016/j.berh.2009.12.005.

Received for publication: 1 October 2010 